International Journal of Computational and

Experimental Science and Engineering

(IJCESEN)

Vol. 3-No.1 (2017) pp. 7-10

http://iakkurt.dergipark.gov.tr/ijcesen

Research Article

\title{
Response Surface Based Optimization of Aerodynamic Performance of a Horizontal Axis Wind Turbine ${ }^{\#}$
}

\author{
Erdem ACAR \\ TOBB University of Economics and Technology, Söğütözü, 06560, Ankara, TURKEY \\ * Corresponding Author : acar@etu.edu.tr
}

(First received 25 November 2016 and in final form 20 February 2017)

\# Presented in " $3^{\text {rd }}$ International Conference on Computational and Experimental Science and Engineering (ICCESEN-2016)"

Keywords
Response surface
Optimization
Wind turbine

\begin{abstract}
Risoe wind turbine is a $100 \mathrm{~kW}$ horizontal axis wind turbine developed by Denmark Technical University National Laboratory for Sustainable Energy to be used for field testing purposes. In this paper, the chord and twist distributions of Risoe wind turbine blades are optimized so that the power production of the wind turbine is maximized. To constrain the mass of the wind turbine blade, the projected surface area of the blade is constrained by its original value. 18 design variables are used to describe the chord and the twist distributions of the blades. The upper and lower bounds of the design variables are taken as $130 \%$ and $70 \%$ of the original values of the design variables, respectively. The fmincon function of MATLAB based on sequential quadratic programming algorithm is used to solve the optimization problem. A response surface based approach to reduce the computational cost. The optimization results show that the power generated by the wind turbine is increased by $20 \%$ through adjusting the chord and twist distributions. It is also found that the response surface based optimization and direct optimization yield nearly the same results, whereas the response surfaces reduce the computational cost by $85 \%$.
\end{abstract}

\section{Introduction}

Wind turbines convert the kinetic energy in the wind into mechanical power, which can be converted into electricity by using generators [1]. Modern wind turbines can be broadly categorized into two groups: horizontal axis and vertical axis wind turbines [2]. Turbine blades rotate on a vertical axis shaft in vertical axis wind turbines (VAWTs), whereas the blades are connected to a shaft that rotates on a horizontal axis in horizontal axis wind turbines (HAWTs). Although VAWTs have some advantages over HAWTs in terms of ease of operations and noise, they cannot produce power as efficiently as HAWTs; thus, HAWTs are more commonly used [2]. The aerodynamic efficiency of a wind turbine is substantially influenced by the aerodynamic shape of wind turbine blades. The taper and twist distributions along the blade span, and cross section profiles of the wind turbines were optimized in earlier studies to maximize the aerodynamic efficiency [3-4]. To reduce the computational cost associated with optimization, response surface approximations can be used to relate the turbine blade design variables to aerodynamic performance metrics [5]. In this study, the chord and twist distributions of Risoe wind turbine blades are optimized so that the power production of the wind turbine is maximized. To constrain the mass of the wind turbine blade, the projected surface area of the blade is constrained by its original value.

\section{Estimation of the Power Produced by the Wind Turbine Using BEMT}

BEMT is one of the oldest and most commonly used methods for evaluating the aerodynamic performance of wind turbines. BEMT is a combination of the blade element theory and momentum theory [6]. In blade element theory, the blades are divided into a number of elements that operate as two-dimensional hydrofoils and the 
aerodynamic behaviors of the elements are assumed to be independent of one another. The aerodynamic forces on the elements are calculated on the basis of local flow conditions. Total force and moment on the turbine are calculated by integrating the element forces along the wing span. In momentum theory, the work done by the air flow on the blade elements is the main cause of loss of pressure or momentum. The momentum losses in axial and tangential directions can be calculated by using the induced velocities in the axial and tangential directions. Then, the thrust and moment at each blade element are computed and integrated to obtain the overall turbine thrust and torque. Finally, the power output is computed by multiplying the torque and the rotational speed. In this study, the power generated by the wind turbine is evaluated using WT_Perf software that uses BEMT.

\section{Problem Definition}

Risoe wind turbine is a $100 \mathrm{~kW}$ horizontal axis wind turbine developed by Denmark Technical University National Laboratory for Sustainable Energy to be used for field testing purposes. Table 1 provides the geometrical characteristics of Risoe wind turbine, and Figures 1 and 2 present the twist and taper distributions.

Table 1. General characteristics of Risoe WT

\begin{tabular}{|l|l|l|l|}
\hline $\begin{array}{l}\text { Number of } \\
\text { Blades }\end{array}$ & 3 & $\begin{array}{l}\text { Root } \\
\text { extension }\end{array}$ & $2.3 \mathrm{~m}$ \\
\hline $\begin{array}{l}\text { Turbine } \\
\text { diameter }\end{array}$ & $19 \mathrm{~m}$ & $\begin{array}{l}\text { Blade set } \\
\text { angle }\end{array}$ & 1.8 degree \\
\hline $\begin{array}{l}\text { Rotational } \\
\text { Speed }\end{array}$ & $\begin{array}{l}47.5 \\
\mathrm{rpm}\end{array}$ & $\begin{array}{l}\text { Maximu } \\
\mathrm{m} \text { Twist }\end{array}$ & 15 degree \\
\hline $\begin{array}{l}\text { Cut-in wind } \\
\text { speed }\end{array}$ & $4 \mathrm{~m} / \mathrm{s}$ & $\begin{array}{l}\text { Root } \\
\text { Chord }\end{array}$ & $1.09 \mathrm{~m}$ \\
\hline Control type & Stall & $\begin{array}{l}\text { Tip } \\
\text { Chord }\end{array}$ & $0.45 \mathrm{~m}$ \\
\hline Rated power & $\begin{array}{l}100 \\
\mathrm{~kW}\end{array}$ & Airfoil & $\begin{array}{l}\text { NACA 63- } \\
\text { 4xx series }\end{array}$ \\
\hline
\end{tabular}

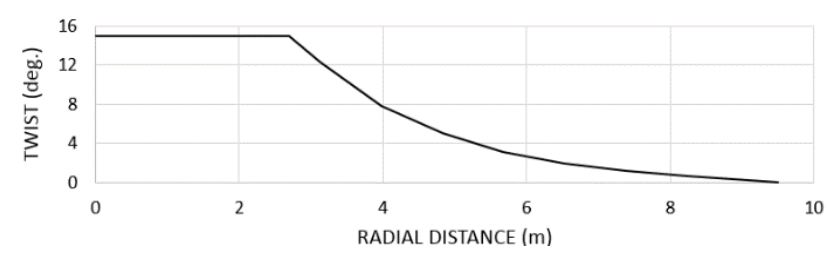

Figure 1. Twist distribution of Risoe WT blades along the blade span

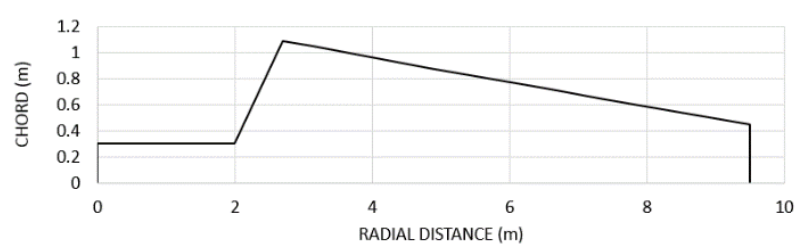

Figure 2. Taper distribution of Risoe WT blades along the blade span

In this study, the number of blade elements used in BEMT is taken 10. The initial values of the chord and twist at each element are given in Table 2. In optimization, the twist and chord values corresponding to the elements 2 through 10 are taken as design variables, therefore the total number of design variables is 18 . The power output of the wind turbine with the initial chord and twist values is computed as $102.7 \mathrm{~kW}$ by using WT_Perf software.

The objective function used in optimization is the power output of the wind turbine. To constrain the mass of the wind turbine blade, the projected surface area of the blade is constrained by its original value. The upper and lower bounds of the design variables are taken as $130 \%$ and $70 \%$ of the original values of the design variables, respectively. The fmincon function of MATLAB based on the sequential quadratic programming algorithm is used to solve the optimization problem.

Table 2. Initial chord and twist distribution and the design variables (shown in bold fonts)

\begin{tabular}{|c|c|cc|cc|}
\hline $\begin{array}{c}\text { Elem. } \\
\text { No. }\end{array}$ & $\begin{array}{c}\text { Radius } \\
(\mathrm{m})\end{array}$ & \multicolumn{2}{|c|}{$\begin{array}{c}\text { Twist } \\
\text { (deg) }\end{array}$} & \multicolumn{2}{|c|}{$\begin{array}{c}\text { Chord } \\
\text { (m) }\end{array}$} \\
\hline 1 & 1.425 & 15.00 & & 0.3000 & \\
\hline 2 & 2.275 & 15.00 & (DV1) & 1.0900 & (DV10) \\
\hline 3 & 3.125 & 12.25 & (DV2) & 1.0475 & (DV11) \\
\hline 4 & 3.975 & 7.80 & (DV3) & 0.9650 & (DV12) \\
\hline 5 & 4.825 & 5.00 & (DV4) & 0.8850 & (DV13) \\
\hline 6 & 5.675 & 3.15 & (DV5) & 0.8050 & (DV14) \\
\hline 7 & 6.525 & 1.95 & (DV6) & 0.7250 & (DV15) \\
\hline 8 & 7.375 & 1.20 & (DV7) & 0.6450 & (DV16) \\
\hline 9 & 8.225 & 0.65 & (DV8) & 0.5650 & (DV17) \\
\hline 10 & 9.075 & 0.20 & (DV9) & 0.4850 & (DV18) \\
\hline
\end{tabular}

\section{Response Surface Based Optimization}

Response surface (RS) models are approximate mathematical models used as surrogate models for the responses of computationally intensive simulations [7]. In this study, we use linear response surface of the form 


$$
\hat{f}(x)=b_{0}+\sum_{i=1}^{L} b_{i} x_{i}
$$

where $\hat{f}$ is the RS approximation of the actual response function $(f), L$ is the number of variables in the input vector $\boldsymbol{x}, b_{0}$ and $b_{i}$ are the unknown coefficients determined by the least squares technique.

To construct an RS, a set of training points are generated first. In this study, Latin hypercube sampling is used to generate the training points. The number of training points is taken as twice the number of coefficients in the RS model. Therefore, 38 training points are generated in this study. Then, the response (the power output of the wind turbine) is computed at the training points. Next, the coefficients in the RS model are determined by the least squares technique. The accuracy of the constructed RS model is evaluated at the data points by using two error metrics: RMSE and $\mathrm{R}^{2}$. The RMSE at the training points is evaluated as $0.6 \mathrm{~kW}$. This RMSE value is only $0.6 \%$ of the nominal value $102.7 \mathrm{~kW}$, indicating a good accuracy. Similarly, the coefficient of determination $\mathrm{R}^{2}$ at the training points is computed as 0.995 , depicting a high level of accuracy.

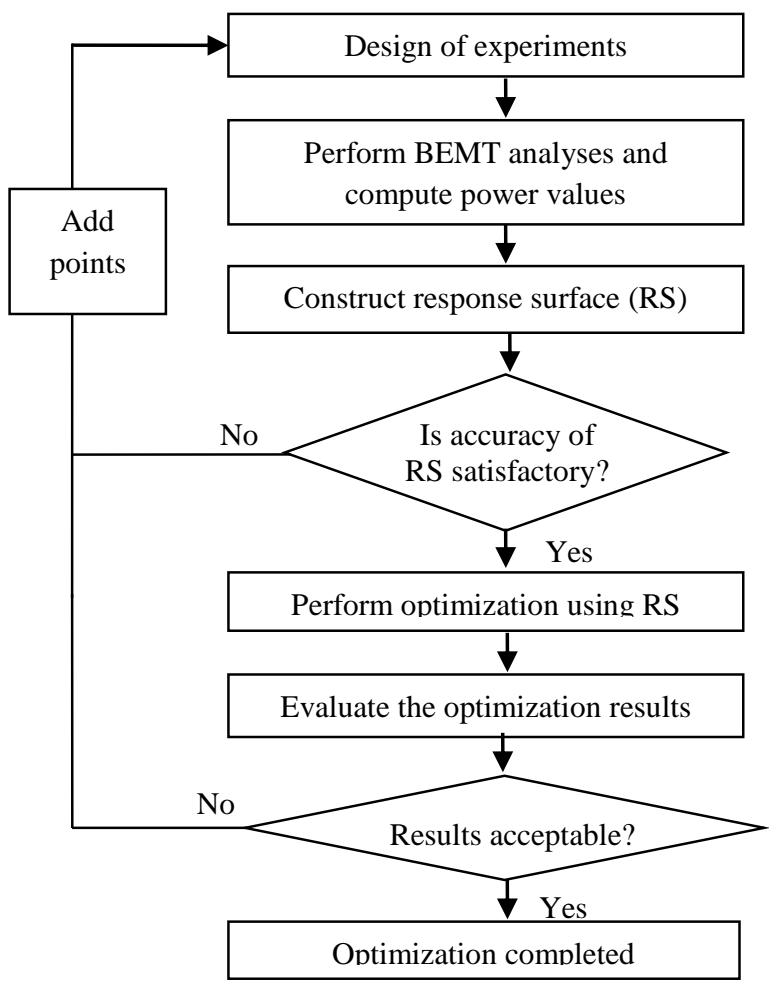

Figure 3. Response surface based optimization methodology followed in this study
The constructed RS models is finally integrated into optimization and the optimal twist and chord values at blade elements are obtained. The response surface based optimization methodology followed in this study is shown in Fig. 3.

\section{Optimization Results}

To provide a basis for comparison with the optimization using RS, the optimization problem is solved without using RS (i.e., solved through direct optimization). The WT_Perf software is directly integrated into the fmincon optimizer of MATLAB and the optimization problem is solved. The optimization is converged in 13 iterations, and the overall number of power output calculations for optimization is 247 . The optimum power output is computed as $123.6 \mathrm{~kW}$. The power output of the optimized design is $20 \%$ larger than that of the initial design.

Next, the optimization problem is solved by using RS. The total number of power output calculations is only 38. That is, the use of response surfaces reduces the computational cost by $85 \%$ compared to the direct optimization. The optimum power output obtained through response surface based optimization is computed as $123.5 \mathrm{~kW}$. This value is only $0.1 \mathrm{~kW}$ smaller than that of the direct optimization result $(123.6 \mathrm{~kW})$. The comparison of the initial and optimum twist distributions and chord distributions are also shown in Figs. 4 and 5. It is observed that the optimization results achieved by using RS are nearly the same as the ones achieved through direct optimization.

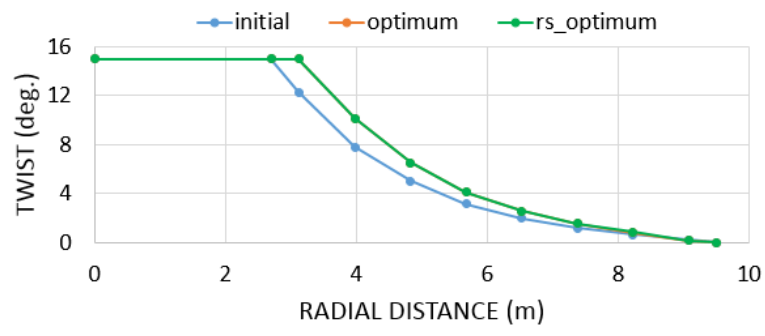

Figure 4. Initial and optimum twist distributions

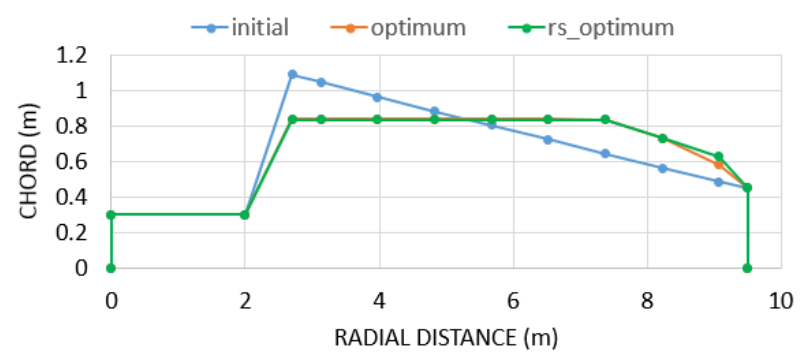

Figure 5. Initial and optimum chord distributions 
Response surface based optimization of wind turbines blades is also investigated by Carrasco et al. [5]. They used Kriging models as response surface models. The chord and twist distribution along with the airfoil profiles were optimized. Overall, 42 design variables were considered and 420 BEMT analyses were performed. The power production was increased by around $23 \%$. In this study, chord and twist distribution were optimized, but the airfoil profile was kept unchanged. Overall, 18 design variables are considered and 38 BEMT analyses were performed. The power production is increased by around 20\%. The computational expense of this study is much smaller compared to the study of Carrasco et al. [5].

\section{Conclusion}

In this paper, the chord and twist distributions of Risoe wind turbine blades were optimized so that the power production of the wind turbine was maximized while the projected surface area of the blade was constrained by its original value to constrain the blade mass. The power produced by the wind turbine was estimated by using blade element momentum theory. Optimization was performed by using a response surface based approach to reduce the computational cost. It was found that the power generated by the wind turbine was increased by $20 \%$ by adjusting the chord and twist distributions. It was also found that the response surface based optimization and direct optimization results were nearly the same, whereas the computational cost is reduced by $85 \%$ by using response surfaces.

\section{Acknowledgement}

The financial support provided by The Scientific and Technological Research Council of Turkey (TÜBITAK), under award 214M205, is gratefully acknowledged.

\section{References}

[1] Burton, T., Sharpe, D., Jenkins, N., Bossanyi, E., "Wind Energy Handbook," Wiley, New York, NY, 2001.

[2] Hau, E., "Wind Turbines - Fundamentals, Technologies, Applications, Economics," SpringerVerlag, Berlin, 2013.

[3] Jureczko, M., Pawlak, M., Mężyk, A., "Optimisation of wind turbine blades," Journal of Materials Processing Technology, Vol. 167, No. 23, 2005, pp. 463-471.
[4] Wang, Q., Wang, J., Chen, J., Luo, S., Sun, J., "Aerodynamic shape optimized design for wind turbine blade using new airfoil series," Journal of Mechanical Science and Technology, Vol. 29, No. 7, 2015, pp. 2871-2882.

[5] Carrasco, A.D., Valles-Rosales, D.J., Mendez, L.C., Rodriguez, M.I., "A site-specific design of a fixed-pitch fixed-speed wind turbine blade for energy optimization using surrogate models," Renewable Energy, Vol. 88, 2016, pp.112-119.

[6] Snel, H., "Review of Aerodynamics for Wind Turbines," Wind Energy, Vol. 6, 2003, pp 203-211.

[7] Myers, R.H., Montgomery, D.C., "Response Surface Methodology: process and product optimization using designed experiments," Wiley, New York, NY, 2002. 